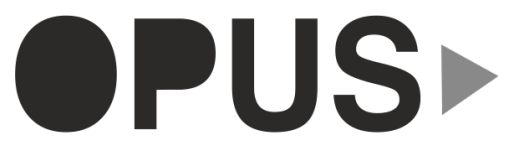

Uluslararası Toplum Araştırmaları Dergisi International Journal of Society Researches
E-ISSN : 2528-9535

YIl Year: 9

Cilt Volume: 14

Sayı Issue :20

Aralık December 2019

Makalenin Gelis Tarihi Received Date: 08/08/2019

Makalenin Kabul Tarihi Accepted Date: 12/12/2019

\title{
Ergenlerle Diyalektik Davranış Terapisi
}

\author{
DOI: 10.26466/opus.604025
}

\section{Mehmet Akif Karaman *}

* Dr. Öğr Üyesi, Kilis 7 Aralık Üniversitesi, Muallim Rıfat Eğitim Fakültesi, Kilis / Türkiye E-Posta: makaraman@gmail.com

ORCID: $\underline{0000-0001-7405-5133}$

\section{Öz}

Diyalektik Davranış Terapisi (DDT) üçüncü dalga terapiler içinde yer alan ve deneysel olarak farklı gruplarla sınanmış yaklaşımlardan biridir. Marsha Linehan tarafından 1990'ların başında sınırda kişilik bozukluğu tanısı konmuş hastaların iyileştirilmesi amacı ile geliştirilen bu yaklaşım daha sonra farklı problem ve davranış sorunlarıyla da baş etmek için kullanılmıştır. Son yıllarda DDT'nin ergenlerle kullanımı ve ergenlerle çalışan uzmanlara yönelik geliştirilen kaynaklar açısından önemli artış vardır. Biyososyal teoriye göre ergenlerin beyni biyolojik olarak farklı çalışmaktadır; bu yüzden, geçici duygular konusunda diğer insanlardan daha kırılgandırlar. Bu çalışma da DDT'nin gelişiminin yanı sıra ergenlerle kullanım alanları, DDT'nin uygulanması ve terapinin basamakları üzerinde durulmuştur. DDT'de danışmaya başlamadan önce danışanın hangi basamakta olduğu tanılanır; bu, daha sonra uygulanacak olan teknik ve yöntemlerin ve terapi süresinin belirlenmesi açısından önem arz etmektedir. DDT dört farklı modül (Bireysel terapi, Beceri eğitimleri, Telefon görüşmeleri, Konsültasyon ekibi toplantıları) halinde uygulanabilmektedir. Ergenlerle en sık kullanılan modül beceri eğitimleri modülüdür. Bunun yanı sıra "standart DDT" olarak adlandırılan ve bireysel terapi ve beceri eğitimlerinin aynı anda kullanıldığı yöntem de çok yaygındır. Ayrıca bu çalışmada alanyazında son yıllarda yapılmış çalışmaların taraması yapılmış ve DDT'nin ergenler üzerindeki etkililiği tartışılmıştır. Çalışmanın, Türkiye'de filizlenmekte olan DDT ve DDT yaklaşımın benimseyen alan uzmanlarına, ruh sağlığı çalışanlarına ve yetişmekte olan öğrencilere kaynak olacă̆ı düşünülmektedir.

Anahtar Kelimeler: Diyalektik davranış terapisi, Ergenlik, Biyososyal teori, Üçüncü dalga terapileri. 


\title{
Dialectical Behavior Therapy with Adolescents
}

\begin{abstract}
Dialectic Behavior Therapy $(D B T)$ is one of the third wave therapies and has been experimentally tested with different groups. This approach, which was developed by Marsha Linehan in the early 1990s to improve patients with borderline personality disorder, was later used to deal with different problems and behavioral issues. In recent years, there has been a significant increase in the use of DBT with adolescents and the resources developed for specialists working with adolescents. According to the biosocial theory, the brain of adolescents work biologically differently; therefore, they are more vulnerable to temporary emotions than other people. In this study, the developments of DBT, as well as its use with adolescents, implementation of DBT and the stages of therapy were emphasized. Before starting counseling in DBT, it is determined which step the client is in. This is important for determining the techniques and methods to be applied and the duration of therapy. DBT can be implemented in four different modules (Individual therapy, Skill trainings, Phone calls, Consultation team meetings). The most commonly used module with adolescents is the skill training module. In addition, the so-called standard $D B T$, which uses individual therapy and skills training at the same time, is very common. In addition, recent studies in the literature were reviewed and the effectiveness of DDT on adolescents was discussed. It is thought that the study will be a resource for field experts, mental health workers and students who adopt DDT approach.
\end{abstract}

Keywords: Dialectical behavior therapy, Adolescent, Biosocial theory, Third wave therapies 


\section{Giriş}

Ergenlik genel anlamda birçok biyolojik, sosyal ve psikolojik değişimin yaşandığ 1 bir dönemdir. İnsan hayatında önemli bir yeri olmakla beraber biran da olup biten değişimleri değil süreç içerisine yayılan ve bireylerin (ergenlerin), farklı duyguları aynı anda yaşamasına neden olan bir zaman dilimi olarak karakterize edilebilir. Bu süreç içerisinde birey, kimliğinin farklı yönleri ile karşılaşır. Ergenin, duygu, düşünce ve davranışları arasında yaşadığı gel-gitler, sıkıntıya gösterdiği tolerans, farkındalık, insanlarla olan ilişkileri ve verdiği kararlar hayata olan bakışını ve durduğu yeri de göstermektedir.

Son yıllarda ergenlerin psikolojik dayanaklılığını ve koruyucu ruh sağlığ (bakınız Brink ve Wissing, 2012; Edwards, Mumford ve Serra-Roldan, 2007; Ricard ve diğerleri, 2018) geliştirilmekte, farklı terapi modelleri kullanılmaktadır. Terapi model ve yaklaşımlarının beslendikleri kuramsal temel, uygulayıcıların profesyonel hazır oluş düzeyleri ve ergenlerin danışan olarak psikolojik danışmaya yaklaşımları uygulamaların etkililiğinde belirleyici olabilmektedir. Alanyazın incelendiğinde, son dönemler de ergenlerle kullanılan, üzerinde birçok çalışma ve yayın yapılan terapilerden biri de Diyalektik Davranış Terapisidir (DDT; bakınız Lenz ve Del Conte, 2018; Rathus ve Miller, 2015; Ricard, Lerma ve Heard, 2013). Diyalektik Davranış Terapisi denince akla ilk gelen kavramlar bilinçli farkındalık (mindfulness) ve onaylamadır (validation). Bilinçli farkındalık, içinde bulunulan anın farkında olma ve o an da duygu ve düşüncelerin sağlıklı bir şekilde yönetilmesini içerir (Hunnicutt Hollenbaugh, 2018). Onaylama ise ergenin içinde bulunduğu çevre ile alakalıdır. Düşünce ve duygulara karşı çıkmak yerine onları radikal bir biçimde kabullenmeyi içerir (Rathus ve Miller, 2015). Diyalektik Davranış Terapisi, her şeyin karşıtlardan oluştuğu (Tez-Antitez) kavramını ifade eden "diyalektiği" kullanır ve değişim, bir karşıt kuvvet diğerinden daha güçlü olduğunda meydana gelir. Bu noktada, DDT'nin temel amacı, bireye stresle başa çıkabilmeleri için ihtiyaç duyacakları becerileri öğretmektir (Bass, van Nevel ve Swart, 2014). 
Ergenlerle farklı ortamlarda (klinikler, okul rehberlik servisleri, psikiyatri servisleri, aile danışmanlı̆̆ı) etkili bir şekilde kullanılan DDT'nin, intihara meyilli olan ve kendine zarar veren ergenlerde de etkili olduğu yapılan çalışmalar da kanıtlanmıştır (Harvey ve Rathbone, 2013). Diyalektik Davranış Terapisinin, düzensiz ergenlerin tipik olarak ihtiyaç duyulan davranışsal başa çıkma becerilerinin eksikliğini, gerçeği olduğu gibi kabul etmeyi ve değişime olan bağlllı̆̆ sürdürmeyi sağlama konusunda yardıma ihtiyaç duydukları üç güçlü alanda davranışı iyileştirdiği kanıtlanmıştır (Arch ve diğerleri, 2012). Bu anlamda, mevcut çalışmanın amacı, geniş kullanım yelpazesine sahip olan DDT'nin temel kavramlarının tanıtılmasının yanı sıra ergenlerle nasıl kullanılabileceğini anlatan ve örnek uygulama planı ile ruh sağlığı profesyonellerinin, DDT'ye ilgi duyan uzmanların ve ruh sağlığı alanında yetişen öğrencilerin yararlanabileceği bir referans kaynağını alanyazına kazandırmaktır.

\section{Diyalektik Davranış Terapisinin Gelişimi}

Diyalektik Davranış Terapisi, Bilişsel Davranış Terapi (BDT) ekolü içerisinde yer alan ve temeline bilinçli farkındalığın ve diyalektlerin yerleştirildiği üçüncü dalga terapilerindendir. Marsha Linehan tarafından 1990'ların başında sınırda kişilik bozukluğu (SKB) tanısı konmuş hastaların (daha çok kadınlar için) iyileştirilmesi amacı ile geliştirilmiştir (Linehan, 1993). Ancak ilerleyen zaman içerisinde DDT farklı konumlarda (hastane, okul, özel klinikler), farklı gruplarda (örn., ergenler, yetişkinler) ve farklı cinsiyetlerde kullanılmaya başlanmıştır. Diyalektik Davranış Terapisinin gelişim sürecine bakıldığında Linehan'ın kişisel deneyimlerinin çok etkili olduğu göze çarpmaktadır. Marsha Linehan zor geçen bir ergenlik ve genç yetişkinlik döneminden sonra (18 yaşında şizofreni tanısı, 26 ay hastane de yatış, kendine zarar verme, en az iki intihar girişimi) psikolojiye merak sarmış ve psikoloji eğitimi almıştır. Daha sonraki yıllarda kendi gençlik dönemiyle özdeşleştirdiği SKB tanısı konmuş bireylerle çalışmaya başlamıştır (Sargın ve Sargın, 2015).

Diyalektik Davranış Terapisi'nin doğuşuna neden olan ve Linehan'ın önemle vurguladığı nokta, SKB tanısı konmuş danışanların terapide tutunabilmesi için danışanın diğer insanlardan daha yoğun yaşadığı öfke, boşluk ve kaygı duygularını kabullenmesi (validation) idi (Sargın ve Sargın, 
2015). Sınırda kişilik bozukluğu olan danışanlarda en sık görülen sorunların başında intihar girişimleri, kendine zarar verme ve sürekli zihni meşgul eden intihar düşünceleri gelmektedir (Üstündağ Budak ve Özeke Kocabaş, 2019). Sürecin başında DDT, ifade edilen bu problemlerle ve özellikle yetişkinlerle etkili bir şekilde kullanılmıştır. Ancak daha sonraları, terapi kaynaklı fazla olan ücret yükünün azaltılması ve zamandan tasarruf edebilme açısından DDT, önleyici/koruyucu bir ruh sağlığı modeli olarak dönüştürülmüş, sorunların temeline gitmek amaciyla problemlerin filizlendiği ergenlik ve çocukluk döneminde olan bireylere ulaşılmış ve geniş kitlelere yayılabilmek için beceri temelli modüller geliştirilmiştir.

Diğer üçüncü dalga terapi türleri (MOD Terapisi, Kabul ve Kararlılık Terapisi) ile karşılaştırıldığında, DDT ergenlerle kullanılan ve deneysel olarak en çok sınanan terapi türüdür (Bass ve diğerleri, 2014). Ancak, hiçbir üçüncü dalga terapisi kaynağından beslendiği BDT kadar yaygın kullanıma sahip değildir. Bunun birkaç nedeni vardır. BDT çok uzun süreden beri kullanılmakta ve eğitim ağını güçlü bir şekilde oluşturmuştur. Diğer taraftan akla şu sorular gelebilir: BDT var iken neden DDT kullanmalıyım? BDT ve DDT arasındaki fark nedir? Bu sorulara cevap verebilmek için Tablo 1'de de belirtildiği gibi BDT ve DDT'nin farklılaşan temel felsefesine, amacına, uygulama alanlarına bakmak gerekir. En başta DDT'nin neden ve hangi şartlar altında ortaya çıtığına bakacak olursak, DDT klasik hale gelen BDT' den odaklandığı danışan kitlesi bakımından ayrışmıştır. DDT daha çok duygusal ve sosyal yönlere odaklanmış, bilinçli farkındalık ve onaylama gibi iki önemli kavram ile insanların düzensiz olan duyguları ve kendilerine zarar veren davranışları ile mücadele edebilmenin önünü açmıştır. BDT ve DDT arasındaki ana farklılıklar onaylama ve ilişkilerdir (Canadian Mental Health Association [CMHA], t.y.). DDT danışanlara, deneyimlerinin gerçek olduğunu ve zorluklardan veya zor deneyimlerden bağımsız olarak kim olduklarını kabul etmelerini öğretir (CMHA, t.y.). DDT'de danışan ve danışman arasında BDT'nin yapıland1rılmış ilişkisinin aksine danışanın danışmana ulaşabileceği ve her an problemlerini ve başarılarını konuşabileceği bir ilişki vardır. BDT becerilerine ek olarak danışan, duygularını düzenlemeyi, diğerleriyle ilişkilerini geliştirmeyi, problemlerle ve sıkıntılarla baş edebilmeyi, kabulü ve bilinçli farkındalığı öğrenir (Bass ve diğerleri, 2014; Hunnicutt Hollenbaugh, 2018). 
Ergenlik duygu düzensizliklerinin en yoğun olduğu ve bazı kişiler için kendini olduğu gibi kabul etmenin en zor olduğu dönemlerden biridir. Bu dönemin yoğun duygularla geçmesinin en önemli nedenleri yaşanan biyolojik, psikolojik ve sosyal değişikliklerdir. Daha genel bir ifade ile biyolojik ve çevresel faktörlerdir. Linehan (1993) bu kavramlara özel önem vermiş ve zaman içinde biyososyal teori terimi kullanılmaya başlanmıştır.

\section{Biyososyal Teori ve Duygu Düzensizliği}

Linehan (1993), duygusal olarak düzensiz olan bireylerin sorunlu davranışlarının bir dizi biyolojik ve çevresel faktörden etkilendiğini iddia etmiştir. Özel olarak, kişinin biyolojik zayıflığ 1 ve içinde bulunduğu çevre

Tablo 1. BDT ve DDT'nin karşılaştırılması (Bass ve diğerleri, 2014, s. 5)

\begin{tabular}{|c|c|c|}
\hline İlkeler & BDT & DDT \\
\hline $\begin{array}{l}\text { Temel } \\
\text { felsefe }\end{array}$ & $\begin{array}{l}\text { Akılcı olmayan düşünme, öğrenmeyle } \\
\text { düzeltilebilen rahatsızlıklara yol açar }\end{array}$ & $\begin{array}{l}\text { BDT'nin ve meditasyona dayal } \\
\text { uzak doğu uygulamalarını birleşti- } \\
\text { rir }\end{array}$ \\
\hline $\begin{array}{l}\text { Anahtar } \\
\text { kavramlar }\end{array}$ & $\begin{array}{l}\text { Sorunların kökeni çocukluğa dayanır; } \\
\text { ancak, mevcut düşünce ve temel inanç- } \\
\text { larla pekiştirilir }\end{array}$ & $\begin{array}{l}\text { Destek odaklı, bilişsel temelli ve iş- } \\
\text { birlikçi terpiyi kullanarak uyarılma } \\
\text { seviyelerini yönetmek için psiko- } \\
\text { sosyal yönleri vurgular }\end{array}$ \\
\hline $\begin{array}{l}\text { Terapinin } \\
\text { amaçları }\end{array}$ & $\begin{array}{l}\text { Akılcı olmayan inanışları yüzleştirir ve } \\
\text { otomatik düşünceyi değiştirir }\end{array}$ & $\begin{array}{l}\text { Stabilize eder, davranıs kontrolünü } \\
\text { sağlar ve travmatik olmayan dene- } \\
\text { yim elde eder }\end{array}$ \\
\hline $\begin{array}{l}\text { Terapötik } \\
\text { ilişki }\end{array}$ & Yönlendirici öğreten-öğrenen ilişkisi & Koşulsuz kabul ilişkisi \\
\hline Teknikler & $\begin{array}{l}\text { Yapılandırılmış bilişsel, davranışçı ve } \\
\text { duygusal teknikler }\end{array}$ & $\begin{array}{l}\text { Farkındalık, kişilerarası etkililik, } \\
\text { duygu düzenleme, sıkıntıya karşı } \\
\text { tolerans ve orta yoldan yürüme be- } \\
\text { cerileri öğretilir }\end{array}$ \\
\hline Kullanımı & $\begin{array}{l}\text { Duygu durum bozuklukları, yeme bo- } \\
\text { zuklukları, psikoz bozukluklar, disso- } \\
\text { siyatif bozukluklar, madde kullanımı }\end{array}$ & $\begin{array}{l}\text { Sınırda kişilik bozukluğu, } \text { duygu } \\
\text { durum bozuklukları, } \\
\text { travma, } \\
\text { madde bağımlılığ }\end{array}$ \\
\hline $\begin{array}{l}\text { Sinırlılık- } \\
\text { ları }\end{array}$ & $\begin{array}{l}\text { Danışanın terapiye bağımlı hale gel- } \\
\text { mesi, yapılandırılmış, yüzleşme de sı- } \\
\text { kıntılar, geçmişe çok az odaklanma }\end{array}$ & $\begin{array}{l}\text { Durağan seyreden tedavi, danışan } \\
\text { beklentileri ve farklılaşmanın ne } \\
\text { kadar etkili olduğunun sorgulan- } \\
\text { ması }\end{array}$ \\
\hline Etkililiği & $\begin{array}{l}\text { Kullanıma bağlı olarak orta ve iyi } \\
\text { düzey arası }\end{array}$ & Düşük ve orta düzey arası \\
\hline
\end{tabular}

(hiçbir şeyi onaylamayan, değer vermeyen) duygusal düzensizliğe zemin 
hazırlamakta (bakınız şekil 1) ve ileride yaşanabilecek muhtemel sıkıntıları tetiklemektedir (Rathus ve Miller, 2018). Duygusal düzensizlik “kişinin en iyi çabasına rağmen, duygusal ipuçları, deneyimler, eylemler, sözlü cevaplar ve / veya normatif koşullar altında sözsüz ifadeleri değiştirme veya düzenleme konusundaki yetersizliğidir" (Koerner, 2012, s.4; akt. Hunnicutt Hollenbaugh, 2018). Bu noktada biyolojik yatkınlık devreye girmektedir. Biyolojik yatkınlığa göre, ergenlerin beyni biyolojik olarak farklı çalışmaktadır; bu yüzden, geçici duygular konusunda diğer insanlardan daha kırllgandirlar (Harvey ve Rathbone, 2013; Hunnicutt Hollenbaugh, 2018; Rathus ve Miller, 2018). Bu ergenler duyguları daha yoğun ve sık yaşayabilirler; bu yüzden duygularını yönetmekte de zorlanabilirler.

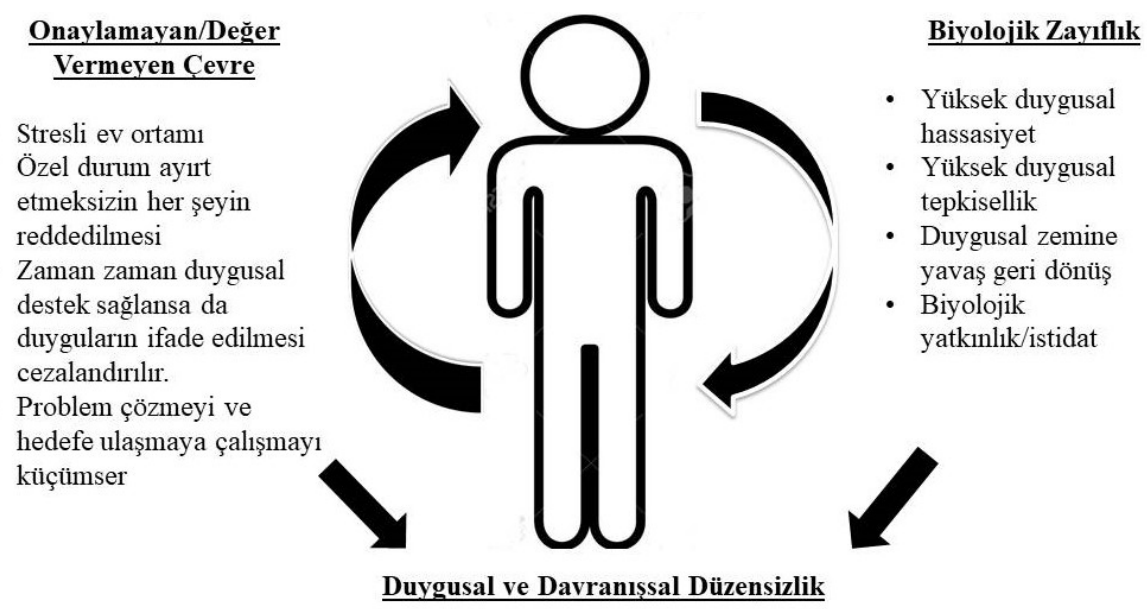

- Uygun bir şekilde duyguların nasıl dışa vurulacağını bilememe

- Olumsuz bașetme yollarına bașvurma (madde kullanma, yeme bozuklukları ve kendine zarar verme Şekil 1. Biyososyal Teori (Hunnicutt Hollenbaugh, 2018)

\section{Diyalektik ve Onaylama}

DDT'nin kendine has bir terim bilgisi vardır ve bu terimleri anlamak DDT'nin anlaşılması için kilit öneme sahiptir. DDT'de en sık kullanılan ve terapiye adını veren "diyalektik" terimidir. Bir diğer terim ise daha önce ifade edilen ve kısaca açılanan onaylama (validation) terimidir. Diyalektik Yunancadan gelir ve "tartışma, söyleşi” anlamlarına gelmektedir. Terapi 
ortamında ise iki zit düşüncenin ya da olgunun doğru olabileceği ve sentezlenip yeni bir düşünce oluşturulabileceği anlamlarına gelmektedir (Linehan, 1993). Linehan'in (1993) bu terimi kullanmasindaki neden ise SKB'ye sahip bireylerde görülen iki düşünce arasında kalmışlık duygusudur. Linehan (1993) SKB'li bireylere hayatın tek renkten oluşmadığını ve aynı anda farklı düşüncelerinde doğru olabileceğini de göstermeye çalışmıştır. Sargın ve Sargının da (2015) vurguladı̆̆ı gibi DDT bardağın ne boş ne de dolu tarafına vurgu yapar. Çünkü bardak hem boştur hem de doludur.

Değişimin başlayabilmesi ve bireyin DDT'den faydalanabilmesi için içinde bulunduğu durumu kabul etmesi gerekir. Danışma ortamında diyalektik danışanları onaylamak için kullanılır. Çünkü DDT varsayım olarak bir danışanın elinden gelenin en iyisini yaptığına ve yapmaya da devam edeceğine inanıyordur. Örneğin annesine öfkelenen bir ergene danışmanın vereceği "Hem annene kızgınsın hem de onu çok seviyorsun. Kızgin olsan da onunla konuşmak istemen anlaşılabilir bir durum" tepkisi bir diyalektik ve onaylama örneğidir. Onaylamanın bir diğer fonksiyonu ise danışanın kabullenmekte zorlandığı olay ve durumların danışma ortamında danışmanın desteği ile normalleştirilmesidir. Örneğin, yeni matematik öğretmeni ile iletişim kurmaktan sürekli kaçan bir lise öğrencisine "yeni matematik öğretmenin sana eski Türkçe öğretmenini hatırlatıyor ve sen onunla hiç iyi şeyler yaşamadın. Bu yüzden Matematik öğretmeninden neden korktuğunu ve onunla iletişim kurmakta zorlandığını anlayabiliyorum" tepkisi danışanı cesaretlendirecek ve anlaşıldığını hissettirecektir.

DDT'de hangi kelimenin ne zaman ve nasıl kullanılacağı önemlidir. Özellikle ergenlere diyalektik düşünme ve cevap verme öğretilirken kullanılan kelimelere vurgu yapılır. Ergenlerin bir olay karşısında tepki vermeden önce o olayı zihinlerinde canlandırmaları ve kendilerinin lehine olacak şekilde nasıl ifade edebilecekleri öğretilir. Bu noktada, cümle kurarken "ya/ya da" gibi zıtlık bildiren kelimelerin yerine onaylama ve sentez bildiren "ve/ hem de" kelimelerinden faydalanılır (Linehan, 2015a). Bu anlamda, terimler kullanıldıkça hem danışman hem de danışan için anlamlı hale gelir. Zaman içerisinde diyalektik düşünme hayatın diğer alanlarına da yayılarak yaşanılan duygu düzensizliklerine denge getirir. 


\section{Terapinin Yapısı ve Uygulanması}

Alanyazın incelendiğinde, yeni başlayanlar için DDT'nin uygulanması kafa karıştırıcı olabilir; ancak terapinin yapısı anlaşıldığı zaman DDT'nin nasıl uygulandığı da açıklık kazanır. Seçilecek yöntem danışmanın kendisine ve danışanın yönteme yaklaşımına bağlıdır. DDT dört farklı şekilde uygulanabilir: a) bireysel terapi, b) beceri eğitimini esas alan psikoeğitim grupları, c) telefon görüşmeleri ve d) konsültasyon ekibi toplantıları (Linehan, 2015a).

DDT'nin dört basamaktan (evre) oluşan bir tedavi süreci vardır. Her bir evre kendine has amaçlara sahiptir. Basamaklar danışanın sahip olduğu sorunların ciddiyetine göre 1 ve 4 arasında numaralandırılmıştır. Bir danışan sadece bir evre de tanı alabileceği gibi aynı anda iki evrede de tanılanabilir. Bu kararı verecek olan danışman ve konsültasyon ekibidir.

1. Basamak: Bu basamak da bulunan ergenler davranışsal kontrolsüzlük yaşayan, temel iletişim becerilerinden yoksun ve kendine zarar verme potansiyeli yüksek danışanlardır. Bu basamakta bireysel danışmanın hedefleri yaşamı tehdit eden, terapi sürecine zarar veren ve hayat kalitesini düşüren davranışsal sorunların azaltılmasıdır. Bunu yapabilmek için de sağ lıklı davranış becerilerinin arttırılması gerekir (Rathus ve Miller, 2018). Bu basamak danışanlarla en çok çalışılan basamaktır. $\mathrm{Bu}$ basamakta bireysel terapiye ek olarak veya sadece beceri eğitimi de verilebilir. Linehan (1993) bu basamakta bulunan ergenelerin her bir beceri eğitimini en az iki kez bitirmesi gerektiğini iddia etmiştir. Bu durumda bu basamakta yer alan bir ergen danışanın terapide geçireceği süre bir yılı bulabilir.

2. Basamak: Bu basamak da tanılanan danışanlar genellikle travma ve yas gibi acı duygusal deneyimlere sahip ergenlerdir. Bu basamaktaki ergenler birinci basamaktaki ergenlerden farklı olarak davranışlarını kontrol edebilirler. Bu evrede uygulanan bireysel danışma oturumları yoğun bir şekilde yapılandırılmıştır. Bu yüzden, psikolojik danışmanın ana hedefi şiddetli duygusal deneyimlerden ve travma sonrası stresten kaynaklı acıdan kaçınmayı azaltıcı becerilerin öğretilmesidir (Linehan, 1993; Rathus ve Miller, 2018).

3. Basamak: Ergenler bazen hayatın akışı ile alakalı sorunlar yaşayabilirler. Örneğin üniversite hayallerini bir yıl ertelemek acı gelebilir, 
mutsuzluğa ve bazı hafif düzey kişilik bozukluklarına neden olabilir. Bu basamak, ergenin mutsuzluğuna neden olan durumlara odaklanır. Terapinin ana amaçları ergenin kendine saygısını arttırmak ve bireysel hedeflerinin gerçekleşmesi için destek olmaktır (Linehan, 1993; Sargin ve Sargin, 2015).

4. Basamak: Son basamak hayata dair anlamsızlık hissi taşıyan ve yaşamdan doyum alamadığını ifade eden ergenler için uygun görülen basamaktır. Bu basamakta bireysel terapinin ana amaçları boşluk ve anlamsızlık hislerinin bir çözüme kavuşturulması ve ruhun özgürleştirilip danışanın huzura kavuşturulmasıdır (Linehan, 1993; Rathus ve Miller, 2018; Sargın ve Sargın, 2015).

\section{DDT Terapi Modülleri}

\section{Bireysel Terapi}

Bireysel terapi standart DDT uygulamasının ana unsurlarından birdir. Bireysel terapi oturumları haftada bir yapılır ve gerekli görüldüğünde aynı hafta içinde tekrarlanabilir. Yetişkinlerde terapi süresi 50-60 dakika arasında iken ergenlerde bu süre 40-50 dakika arası olarak tanımlanmaktadır (Linehan, 2015a). Bireysel oturumlar da sık sık danışanın terapiye düzenli gelmesi gibi konuların yanı sıra yaşamı tehdit eden olaylara müdahale etme, hayat kalitesi ile ilgili davranışları yönetme ve müdahale yöntemleri ile ilgili konular da değerlendirilir (Hunnicutt Hollenbaugh, 2018). Beceri eğitimi gruplarında verilen ev ödevleri ve günlük kartların ayrıntılı değerlendirilmesi yapılır. DDT danışma teknik ve yöntemleri problem durumuna göre uygulanır. Ayrıca, aile süreç içerisine dâhil edilir. Ailenin oturumlara katılması belli haftalarda olacağı gibi ihtiyaç halinde de ayarlanabilir.

\section{Beceri Ĕ̈itimleri}

DDT beceri eğitimleri standart DDT'nin önemli bir parçası olduğu gibi, bireysel terapiden bağımsız olarak kendi başlarına da kullanılabilirler. Yetişkinlere verilen dört beceri eğitimine (farkındalık, duygusal düzenleme, 
sıkıntıya tolerans, kişilerarası etkililik) ek olarak, ergenlerin bulunduğu gruplarda "orta yoldan yürüme" (walking the middle path) beşinci beceri eğitimi (bakınız Tablo 2) olarak uygulanmaktadır (Harvey ve Rathbone, 2013; Hunnicutt Hollenbaugh, 2018; Miller, Rathus ve Linehan, 2007; Rathus ve Miller, 2018). Geleneksel olarak beceri eğitimleri grup danışması olarak verilir, en az dört en fazla 10 danışandan oluşur, haftalık düzenlenir ve ortalama iki saat sürer (Hunnicutt Hollenbaugh, 2018). Eğitimlerin ilk saati ev ödevlerinin ve günlük kartların kontrol edilmesi ile geçer. İkinci saatte ise yeni becerilerin öğretilmesine geçilir. Her oturum bir farkındalık etkinliği ile başlar ve biter. Grup lideri farkındalık etkinliklerini kendi yapabileceği gibi grup üyelerinden gönüllü olanlara da yaptırabilir.

\section{Telefon Görüşmeleri}

Bu yöntem de amaç, danışanın öğrenmekte güçlük çektiği becerileri ihtiyaç duyduğu anda danışmanını arayarak bilgi ve cesaret alabilmesidir. Linehan (1993), düşünülenin aksine danışanların danışmanlarını sık sık rahatsız etmeyeceklerini ve ilgi çekmek için sürekli aramayacaklarını iddia etmiştir. Ancak, burada danışan ve danışman arasında bir taahhüt de konulmuştur. Eğer danışan telefon görüşmesinden önce kendisine zarar vermişse 24 saat boyunca danışmanıyla görüssemez. Buradaki mantık danışanın danışmana bağımlı olmasını engellemektir (Sargın ve Sargın, 2015). Telefon desteği sadece danışana değil ergenlerin ailelerine de verilebilir. Bu sayede aileler de becerilerini geliştirebilirler.

\section{Konsültasyon Ekibi Toplantıları}

Konsültasyon grup toplantıları DDT'de önemli yere sahiptir. Danışanların kendilerine zarar verme davranışları, intihara eğilimli olmaları ve duygusal düzensizlikleri danışmanları süreç içerisinde yıpratabilmektedir(Linehan, 1993).

Konsültasyon ekibi danışmanlara destek sağlar. Grup içerisinde DDT terapistleri olduğu kadar doktorlar, hemşireler, program yöneticileri ve diğer çalışanlar da olabilir. Grubun mevcut üyeleri anlaşılacağı üzere DDT'nin uygulandığı kuruma göre değişebilir. Örneğin, okul ortamında 
uygulandığı zaman konsültasyon ekibinde okul psikolojik danışmanı(ları), idareyi temsilen müdür veya müdür yardımcısı, sınıf öğretmeni, okul aile birliği temsilcisi ve varsa okul hemşiresi yer alır.

Tablo 2. DDT Beceri Grupları (Linehan, 2015a; Miller ve diğerleri, 2007)

\begin{tabular}{|c|c|c|c|c|}
\hline Farkındalık & $\begin{array}{l}\text { Duygusal } \\
\text { Düzenleme }\end{array}$ & $\begin{array}{l}\text { Sikintıya } \\
\text { Tolerans }\end{array}$ & $\begin{array}{l}\text { Kişilerarası } \\
\text { Etkililik }\end{array}$ & $\begin{array}{l}\text { Orta } \\
\text { Yoldan Yürüme }\end{array}$ \\
\hline $\begin{array}{l}\text {-DDT'nin } \\
\text { temelini } \\
\text { oluşturur ve her } \\
\text { oturumda uy- } \\
\text { gulanır } \\
\text { - Mevcut andaki } \\
\text { bilinçliliği ve } \\
\text { kişinin duygu } \\
\text { ve düşün- } \\
\text { celerini } \\
\text { yönetebilme } \\
\text { becerisini art- } \\
\text { tırmayı hedefler } \\
\text { - Hedef, bir şeye } \\
\text { yargılamadan } \\
\text { ve etkili bir } \\
\text { şekilde } \\
\text { odaklanmaktır }\end{array}$ & $\begin{array}{l}\text { - Sadece duygu- } \\
\text { larla baş et- } \\
\text { menin yollarını } \\
\text { değil onların } \\
\text { biyolojik köken- } \\
\text { lerini de öğretir } \\
\text { - Hem fiziksel } \\
\text { hem de zihinsel } \\
\text { olarak farkında } \\
\text { olabilecekleri } \\
\text { yollar öğretir } \\
\text {-Sadece } \\
\text { kendilerinin } \\
\text { değil } \\
\text { başkalarının da } \\
\text { duygularına } \\
\text { odaklanabil- } \\
\text { meyi sağlar }\end{array}$ & $\begin{array}{l}\text { - Sadece ergenin } \\
\text { hemen } \\
\text { değiştiremey- } \\
\text { eceği } \\
\text { durumlarla } \\
\text { karşı karşıya } \\
\text { kaldığında nasıl } \\
\text { baş edeceğini } \\
\text { içermektedir } \\
\text { - Bu durumlar } \\
\text { kriz anları, inti- } \\
\text { har anları ve } \\
\text { yaşamı tehdit } \\
\text { eden diğer du- } \\
\text { rumlar olabilir } \\
\text {-Problem } \\
\text { çözmeye } \\
\text { dayalıdır ve } \\
\text { gerçek duru- } \\
\text { mun radikal bir } \\
\text { şekilde } \\
\text { kabulüne } \\
\text { dayanmaktadır }\end{array}$ & $\begin{array}{l}\text {-Ergenlerin } \\
\text { uğraşmakta } \\
\text { zorlandıkları } \\
\text { değişken ilişkilere } \\
\text { odaklanmaktadır. } \\
\text { - Temelde, kişinin } \\
\text { bir ilişkide kendisine } \\
\text { saygıya, başkalarına } \\
\text { saygıya, atılgan } \\
\text { olarak ihtiyaçlarını } \\
\text { karşılamaya } \\
\text { ve sağlıklı } \\
\text { ilişkileri başarılı ve } \\
\text { bir şekilde } \\
\text { değerlendirmeyi ve } \\
\text { yönlendirmeye } \\
\text { dayanmaktadır } \\
\text { - Beceriler daha çok } \\
\text { kısaltmalardan } \\
\text { oluşan ve problem } \\
\text { çözme becerileri ile } \\
\text { alakalı kişilerarası } \\
\text { etkililik, ilişkiler } \\
\text { hakkındaki mitleri, } \\
\text { ilişkilerdeki öz } \\
\text { benliği ve ilişkilerde } \\
\text { nasıl davranmamızı } \\
\text { etkileyen kırıl- } \\
\text { ganlıkları içermekte- } \\
\text { dir }\end{array}$ & $\begin{array}{l}\text {-Daha çok ergen- } \\
\text { lere has diyalek- } \\
\text { tik ikilemlere } \\
\text { odaklanmak- } \\
\text { tadır (Duygusal } \\
\text { kırılganlığa karşı } \\
\text { kendi gücünü } \\
\text { azaltma. Aşırı } \\
\text { esnekliğe karşı } \\
\text { otoriter kontrol. } \\
\text { Sürekli krize } \\
\text { karşı çekingen } \\
\text { yaşama. Aktif } \\
\text { pasifliğe karşı } \\
\text { belirgin yeter- } \\
\text { lilik. Özerkliği } \\
\text { zorlamaya karşı } \\
\text { bağımlılığı } \\
\text { teşvik etme) } \\
\text { - Hayatta sadece } \\
\text { siyah ya da } \\
\text { beyaz yok gri de } \\
\text { vardır }\end{array}$ \\
\hline
\end{tabular}

Gruplar şehirde bulunan ve DDT çalışan diğer akıl sağlığı uzmanlarının bir araya gelmesi ile de oluşturulabilir. Gruplar ihtiyaca binaen hafta da bir toplanır ve beceri eğitimlerindeki düzen içerisinde ilerler. Danışma gruplarında veya oturumlarında problem yaşayan danışmanlara destek sağlanır. Her grup farkındalık etkinliği ile başlar ve bitirilir. Bu sayede DDT danışman-danışan-aile/yakın çevre zincirinde topluma yayılmış bir "felsefe" haline dönüşür. 


\section{Ergenlerle DDT Üzerine Yapılan Çalışmalar}

Son yıllarda DDT'nin ergenlerle kullanımı ve etkililiği üzerine birçok araştırma yapılmıştır. Ancak, Türkiye' de DDT'nin kullanımı henüz yaygınlaşmadığı için bu alanda yapılan çalışmalara pek rastlanılmamaktadır. Diyalektik Davranış Terapisi'nin Türkiye' de yaygınlığını etkileyen birçok neden vardır. Bunlardan en önemlileri, eğitim verecek kurum ve uzmanların az olması, Türkçe yazılmış kaynakların çalışma ve uygulama yapmayı destekleyecek düzeyde olmaması ve DDT sürecinde süpervizyon hizmeti verecek uzmanların sayı olarak yetersizliği gösterilebilir. Birçok veri tabanının incelenmesi sonucunda, Gülgez ve Gündüz (2015) tarafından üniversite öğrencileri ile yapılan DDT temelli duygu düzenleme programının Türkiye'de DDT ile yapılmış tek araştırma olduğu bulunmuştur. Ergenlerle yapılmış herhangi bir çalışmaya rastlanmamıştır.

Türkiye dışında özellikle de Amerika Birleşik Devletlerinde (ABD) son on yılda DDT'nin kullanımı hızla yayılmıştır. Marsha M. Linehan'ın öncülüğ̈̈nde başlayan bu terapi ardı ardına yayınlanan kitaplar, kullanım kılavuzları ve deneysel çalışma sonuçları ile büyümesine devam etmektedir. Ergenlerle DDT üzerine çalışma ve uygulama yapmak isteyen uzmanlar için Hunnicutt Hollenbaugh ve Lewis (2018), Linehan (2015a, 2015b), ve Rathus ve Miller (2018) tarafından yazılan kitaplar önemli kaynaklar olarak gösterilebilir.

Ergenlerle DDT'nin etkililiğini gösteren birçok çalışma vardır. Bu çalışmalardan ilki Goldstein, Axelson, Birmaher ve Brent (2007) tarafından yapılmıştır. Goldstein ve arkadaşları (2007) bipolar bozukluk tanısı konmuş 12 ve 18 yaş arası 10 ergene 36 oturumdan (18 oturum beceri eğitimi, 18 oturum bireysel danışma) oluşan DDT programını uygulamış ve sürece aileleri de katarak psikoeğitimler vermişlerdir. Program boyunca bireysel terapi ve beceri eğitimlerinin yanı sıra becerilerin kullanılmasını teşvik eden telefon görüşmeleri ve uyku düzenini, intihar durumunu, ilaç kullanımını değerlendiren günlük kartlar kullanılmıştır. Terapi, ilaç kullanımını da içermiş ve çalışma sonunda intihar düşüncesi, kendine zarar verme davranışı, duygusal düzensizlik ve depresif belirtilerde tedavi öncesinden tedavi sonrasına belirgin iyileşmeler tespit edilmiştir. 
Groves, Backer, van den Bosch ve Miller (2012) tarafından yapılan çalışma da DDT'yi içeren ve 1997-2008 arasında yayınlanmış 12 makale incelenmiştir. Bulgular, DDT'nin ergenler için çeşitli terapötik etkileri olduğunu göstermiştir. Groves ve arkadaşlarının (2012) dikkat çektikleri önemli bir nokta ise intihara meyilli olan ve bipolar bozukluk tanısı konmuş ergenlerin DDT programından veya tedavi sürecinden daha erken ayrıldığıydı. Bunun bir sonucu olarak da programdan ayrılmayan ergenlere göre hastaneye yatışlarında bir artma olduğu ve intihar dâhil olmak üzere birçok olumsuz sonuçla karşı karşıya kaldıklarını belirtmişlerdir.

Bir başka meta-analiz çalışmasında Hunnicutt Hollenbaugh ve Lenz (2018) ergenler için DDT'nin etkinliğine ilişkin ön kanıtları incelemiştir. Çalışmada DDT'nin depresyon, kaygı, kendine zarar verme ve intihar riski belirtilerinin azaltılmasını hedefleyen toplamda 834 katılımcının olduğu 12 adet deneysel çalışma incelenmiştir. Çalışma da bahsi geçen belirtilerin hepsinde ergenlerde bir azalma görüldüğü ancak bunun etkisinin küçükten orta düzeye değiştiği belirtilmiştir. Önemli bulgulardan biri de DDT'nin ergenlerdeki depresyon belirtilerini azaltma açısından diğer tedavi yöntemleri ile karşılaştırıldığında daha etkili olduğudur. Bulgulara ek olarak yazarlar DDT beceri eğitimlerinin standart DDT tedavi yöntemine göre daha çok tercih edildiğini belirtmişlerdir. Bunun nedenlerine bakıldığında DDT beceri modüllerinin uygulanabilirlik açısından daha anlaşılabilir ve kolay olduğu ve standart DDT tedavisine göre daha az masraflı olduğu söylenebilir.

Ergenlerle yapılan çalışmalar sadece ABD ile sınırlı kalmamıştır. Hjalmarsson, Kåver, Perseius, Cederberg, ve Ghaderi (2008) İsveç'de 15-40 yaş arasında olan 27 ergen ve genç yetişkin kadın ile iki yıl süren bir pilot çalışma yapmışlardır. Katılımcıların hepsi sınırda kişilik bozukluk (SKB) tanısı almış vakalardı. Ayrıca çalışma, SKB ile yakından alakalı olan depresyon, kaygi ve obsesif kompulsif gibi duygusal rahatsızlık veren rahatsızlıkların belirtilerindeki azalmaları da ele almıştır. Bir yılın sonunda yapılan analizlerde adı geçen rahatsızlıkların tümünün ölçek puanlarında tedavi öncesine nazaran önemli düşüşler ve güçlü etkiler tespit edilmiştir. Sonuçlar depresyon ve SKB ölçeğinin alt ölçeklerinde (kişiler arası hassasiyet, kaygı, korku endişesi, paranoya düşünceleri) istatistiki düzeyde anlamlı düşüşler olduğunu göstermiştir. Bunlara ek olarak, intihar eğilimli 
davranışlarda da tedavi öncesi ile karşılaştırıldığında önemli düşüşler olduğu 12 aylık değerlendirmelerde bulunmuştur.

2000 'li yılların başında ve sonlarına doğru yapılan birçok çalışma katılımcı grup olarak kadınları almıştır. Bunda Lineha'nın ergenliği ve genç yetişkinliği süresince kendi kişisel tecrübelerinden ve teorisini geliştirirken kadın katılımcılardan faydalanmış olmasının etkisi olduğu düşünülebilir. Yukarıda bahsi geçen çalışmalara ek olarak James, Taylor, Winmill ve Alfoadari (2008) tarafından yapılan çalışma da bu duruma örnek gösterilebilir. James ve arkadaşları, 1srarlı kasıtlı kendine zarar verme (IKKZ) davranışlarına ve yoğun intihar düşüncelerine sahip kız ergenlerle DDT'nin etkililiğini incelemiştir. Çalışma da beceri eğitimini esas alan grup danışması uygulanmış ve DDT farkındalık, sıkıntıya tolerans, kişiler arası etkililik ve duygu düzenleme modülleri kullanılmıştır. Sonuçlar tüm katılımcların ısrarlı IKKZ davranışlarında anlamlı düzeyde düşüş olduğunu göstermiştir. Ayrıca depresyon ve umutsuzluk puanlarında da anlamlı düzeyde düşüşler bulunmuştur.

İfade edilmeye değer bir başka çalışma ise Johnston, O'Gara, Koman, Baker ve Anderson (2015) tarafından yeme bozukluğu tanısı konmuş ergenlerin DDT beceri eğitimleri ve Maudsley aile terapisi (MAT) yaklaşımı kullanılarak 8 haftalık yoğunlaştırılmış programa alındığı araştırmadır. $\mathrm{Bu}$ çalışmanın temelini aile temelli terapi yaklaşımı oluşturmaktadır. Araştırma da kullanılan ana yaklaşım MAT'dir. Diyalektik Davranış Terapisi beceri eğitimleri, ergenlere yeme bozukluğu davranışlarının yerine koyabilecekleri etkili baş etme becerileri sağlamak ve düzenli ve sağlıklı beslenememe sıkıntısına katlanacak yöntemleri hazırlamak amacıyla kullanılmıştır. Çalışmanın ana hedefleri, kilo alma / sağlıklı kilo verme kontrolünün sağlanması ve kısıtlama, aşırı yeme ve kendini kusturma gibi yeme bozukluğu davranışlarının azaltılmasıydı. Çalışmada DDT beceri grupları farkındalık, duygu düzenleme, sıkıntıya tolerans, kişilerarası etkililik ve orta yoldan yürüme becerilerinin yeme bozukluğu kavramı içerisinde öğretilmesine ve uygulanmasına odaklanmıştır. Çalışma da ergenler ve aileleri farklı farklı gruplara katılmış ve aileler çocuklarına verilen beceri eğitimlerinin aynısını almışlardır. Her bir modül 2 hafta sürmüştür. Sonuçlar, kilo alma problemi olan danışanların tedavi süresince önemli miktarda kilo aldıklarını ve sonraki yıl boyunca kilo almaya devam ettik- 
lerini göstermiştir. Programı tamamlayan ergenlerin yeme bozukluğu düşüncelerinde, tutumlarında ve davranışlarında da önemli düşüş yaşandığ 1 rapor edilmiştir. Ancak, Johnston ve diğerleri (2015) aşırı yeme ve bilinçli kusma davranışlarında çalışma sonunda ve takip eden yıl içerisinde anlamlı bir gelişme bulamadıklarını ifade etmişlerdir.

Bahsi geçen çalışmaların çoğu ya bir hastanenin psikiyatri servisinde ya da ayakta tedavi veren kliniklerde gerçekleştirilmiştir. Ancak son yıllarda üniversitelerin psikolojik danışma birimlerinde, okul psikolojik danışma servislerinde ya da proje destekli hastane ve klinik dışı ortamlarda da DDT kullanılmaya başlanmıştır. Örneğin, Ricard ve arkadaşları (2013) ABD'nin Teksas eyaletinde, ağırlıklı olarak Latin Amerika kökenli ortaokul ve lise öğrencilerinden oluşan ve disiplin temelli alternatif eğitim programının uygulandığı bir okulda DDT beceri modüllerinin kullanıldığı, grupla psikolojik danışma yapmışlardır. Kullanılan DDT beceri modüllerinin amacı duygusal ve davranışsal kendini koruma becerilerinin öğretilmesidir. Ricard ve diğerleri (2013) bunu, ergenlerin kendi davranışlarını kontrol etmeyi öğrenirken aynı zamanda davranışlarının çevreleri üzerindeki etkilerinin farkında olmalarını sağlamak olarak da açıklamışlardır. Ortalama bir oturum 2,5 saat sürmüş ve terapi 4 hafta boyunca gerçekleştirilmiştir. Bu çalışmada kullanılan yöntem ve süre standart DDT yaklaşımının (6 ay süren ve haftalık grup danışmalarının yapıldığı sistem) uyarlanmış halidir. Ricard ve arkadaşları programın dört hafta şeklinde düzenlenmesinin sebebi olarak okul sistemindeki öğrencilerin geçici süre ile bu okula aktarıldıklarını ve kendilerine verilen disiplin cezasının süresi dolduktan sonra kendi okullarına geri gönderilmeleri olarak ifade etmişlerdir. Çalışma da DDT'nin somatik şikâyetler, sosyal dışlanma, saldırganlık, çatışma, hiperaktivite ve depresyon üzerindeki etkililiği deneysel olarak sinanmıştır. Çalışmaya 70'i erkek 55'i kız olmak üzere toplamda 178 öğrenci katılmıştır. Sonuçlar, deney grubunda olan öğrencilerin saldırganlık, çatışma ve hiperaktivite puanlarında kontrol grubunda olanlara nazaran anlamlı düzeyde düşüş olduğunu göstermiştir. Bu çalışmayı diğer çalışmalardan ayıran özelliklerden biri de ergenlere verilen ölçme araçlarının uyarlanmış hali ailelerine de verilmiş ve ergenlerin rapor ettikleri değişimlerle ailelerinin çocuklarında gözlemledikleri değişimler karşılaştırılmıştır. Aileler de araştırma sonuçlarına benzer geri dönütlerde 
bulunmuş, ek olarak çocuklarının sosyal izolasyon, depresyon ve somatik puanlarında da anlamlı düzeyde düşüş bildirmişlerdir.

Bahsi geçen çalışmaların hepsinde DDT'nin istatistiki olarak etkililiği vurgulanmıştır. Ancak, alanyazında aksi sonuçların rapor edildiği çalışmalar da mevcuttur. Bir diğer ifade ile DDT'nin etkili olmadığı ya da diğer terapi türleri ile karşılaştırıldığında daha az etkili olduğunu vurgulayan çalışmalara da rastlanmıştır. Örneğin Apsche, Bass ve Houston (2006) tarafından saldırganlık, davranış ve kişilik problemlerine sahip 20 erkek ergen üzerinde yapılan deneysel çalışma da MOD terapisi ve DDT'nin etkililiği karşılaştırılmıştır. Sonuçlar, uygulanan yönteme bakılmaksızın tüm katılımcıların tedaviden olumlu yönden etkilendiğini göstermiştir. Ancak, veriler MOD terapisinin depresyon ve saldırganlık belirtilerinin azalmasında DDT'den daha etkili olduğunu göstermiştir. Ayrıca Apsche ve arkadaşları (2006) MOD terapisinin DDT'ye göre, çalışmada ele alınan tüm davranışsal ve psikolojik sıkıntıların anlamlı düzeyde düşürülmesinde daha etkili olduğunu ifade etmişlerdir.

Bir meta-analiz çalışmasında Brausch ve Girresch (2012), ergenlerde kendine zarar verme davranışlarının tedavi edilme başarısını gözden geçirmişlerdir. Çalışmalarında 2001-2011 yılları arasında yayınlanmış makaleleri incelemişler ve tedavi yöntemi olarak DDT ve Bilişsel Davranış Terapisini (BDT) ele almışlardır. Yazarlar, son yıllarda ergenler arasında kendine zarar verme davranışlarında bir artış olduğunu ve DDT'nin de bunu azaltmak için en sık kullanılan yöntemlerden biri olduğunu iddia emişlerdir. Analiz sonuçları DDT'nin ergenlerde kendine zarar verme davranışlarını azaltma da yetersiz olduğunu göstermiştir. Brausch ve Girresch (2012) her ne kadar DDT'nin etkili olduğunu gösteren çalışmalar varsa da bu çalışmaların sonuçlarının etkisinin yok denecek kadar az olduğunu iddia etmişlerdir. Bu çalışmada DDT’ye getirilen bir eleştiri de DDT'nin tarihsel olarak Psikiyatri servislerinde çalışmaya daha müsait olduğu ama hastane dışı ortamlarda etkililiğinin azaldığ1 ya da olmadığı yönündeydi. Hiç şüphesiz, bu tür yargılara varabilmek için DDT ile ilgili daha çok çalışmaya ihtiyaç duyulmaktadır. Diğer taraftan, son yıllarda DDT'nin gösterdiği gelişim, oluşturulan kaynaklar ve çalışma sonuçları DDT'nin ergenlerle gelecekte daha çok kullanılacak bir yaklaşım olacağına işaret etmektedir. 


\section{Sonuç}

Bu çalışmanın amacı üçüncü dalga terapileri içinde yer alan ve son yıllarda ergenlerle kullanımı hizla yayılan DDT'nin teori, kavram ve uygulama alanlarının tanıtılması ve ileride ergenlerle yapılacak çalışmalara uzmanların yararlanabileceği bir referans kaynak oluşturmaktır. DDT, özellikle intihara meyilli, kendine zarar verme davranışları sergileyen, depresyon da olan, iletişim becerileri zayıf, öfke kontrolü ve davranış problemleri yaşayan ve duygu düzensizliği sergileyen ergenlerle başarılı bir şekilde kullanıldığı kanıta dayalı çalışmalarda gösterilmektedir. Ergenlerle DDT'yi kullanmak isteyen ve DDT terapisti olmak isteyen bir ruh sağlığ uzmanının bilmesi gereken önemli noktaların başında DDT'nin dört basamaklı tanı sistemine sahip olduğu ve uygulanmasının dört farklı (Bireysel terapi, beceri eğitimi, telefon görüşmeleri, konsültasyon ekibi toplantıları) şekilde yapılabildiği gelmektedir. DDT ergenlerle kullanılırken en sık kullanılan uygulaması beceri eğitimi modülüdür. Beceri eğitimleri ergenler için beş farklı başlıktan oluşmakta ve altı aylık bir süre içerisinde bitirilebilmektedir. Birinci basamakta tanılanmış danışanların beceriler modülünü bir yıllık süre içerisinde iki defa üst üste tekrarlamaları tavsiye edilmektedir (Linehan, 1993).

Ergenlerle çalışırken DDT'nin başarı şansını arttırmanın yollarından biri de ailelerinin de sürece dâhil edilmesidir. İncelenen birçok çalışma da ergenlerle çalışılırken DDT ve aile terapisi yaklaşımlarının beraber kullanıldığı görülmüştür. Burada göze çarpan nokta DDT'nin ergenin sahip olduğu davranış problemini veya problemlerini salt ergene mal etmemesi, aynı zaman da ailenin de bir problemi olarak görmesidir. Henüz Türkiye de ergenlerle yapılmış kanıta dayalı bir çalışma mevcut değildir. İleriki dönemler de bu tür çalışmanın yapılması önemle tavsiye edilmektedir. 


\title{
EXTENDED ABSTRACT
}

\section{Dialectical Behavior Therapy with Adolescents}

\author{
Mehmet Akif Karaman \\ 7 Aralık University
}

Adolescence is a period in which biological, social and psychological changes occur. Although it has an important place in human life, it can be characterized as a period of time that diffuses into the process and causes individuals (adolescents) to experience different emotions at the same time, not the changes that take place.

In recent years, programs to increase adolescents' psychological resilience and preventive mental health skills - especially abroad - have been developed (see Brink and Wissing, 2012; Edwards, Mumford and SerraRoldan, 2007; Ricard et al., 2018) and different models of therapy have been used. When the literature is examined, it has been noted that DBT is one of the therapies used with adolescents in experimental studies. Validation and mindfulness are the core values of DBT. Mindfulness means being aware of the present and managing the emotions and thoughts in a healthy way. Validation is related to the environment in which the adolescent lives. It means accepting thoughts and feelings radically instead of opposing them.

Dialectic Behavior Therapy (DBT) is one of the third wave therapies and has been experimentally tested with different groups. This approach, which was developed by Marsha Linehan in the early 1990s to improve patients with borderline personality disorder, was later used to deal with different problems and behavioral issues. In the course of time, DBT was used in different settings (hospitals, schools, private clinics), groups (adolescents, adults), and gender. When we look at the development process of DBT, we can see that Linehan's personal experiences are very effective. After a difficult adolescence and young adulthood (18 years old, diagnosed with schizophrenia, hospitalization for 26 months, self-harm, at least two suicide attempts), Marsha Linehan became interested in psychology and received psychology education. In the following years, she 
started working with individuals diagnosed with borderline personality disorder (Sargin and Sargin, 2015).

Linehan (1993) argued that problematic behavior of individuals who are emotionally disturbed is affected by a number of biological and environmental factors. Specifically, the person's biological weakness and the environment in which he or she is (who does not approve of anything, does not value) paves the way for emotional disorder and triggers possible future problems (Rathus and Miller, 2018).

The word of dialectic comes from Greek and means "discussion, conversation." In the therapy, it means that two opposing ideas or phenomena can be correct and that a new thought can be synthesized (Linehan, 1993). The adolescent has to accept the situation in order to change and benefit from DBT. The function of approval is to normalize the events and situations in which the client has difficulty accepting with the support of the counselor in the counseling.

DBT can be implemented in four different ways: a) individual therapy, b) psychoeducation groups based on skills training, c) telephone interviews and d) consultation team meetings (Linehan, 2015a). DBT has a four-stage treatment process. Each stage has its own goals. The steps are numbered 1 through 4 depending on the severity of the problems the client has. A client can be diagnosed in only one stage or in two stages at the same time. It is the consultant and consultation team that will make this decision.

The aim of this study is to introduce the theory, concepts and application areas of DBT, which is included in third wave therapies and whose usage has been rapidly spreading with adolescents in recent years. Another goal of the study is to provide a reference resource for future studies with adolescents. DBT has been shown to be successful in evidence-based studies, especially with suicidal, self-injurious behavior, depression, adolescents with poor communication skills, anger control and behavioral problems, and emotion disorder. There is no evidence-based study using DBT conducted with adolescents in Turkey yet. It is strongly recommended that this kind of study be done in the future. 


\section{Kaynakça / References}

Apsche, J. A., Bass, C. K., ve Houston, M. (2006). A one year study of adolescent males with aggression and problems of conduct and personality: A comparison of MDT and DBT. International Journal of Behavioral Consultation and Therapy, 2, 544-552. doi:10.1037/h0101006

Arch, J. J., Eifert, G. H., Davies, C., Vilardaga, J. C. P., Rose, R. D., ve Craske, M. G. (2012). Randomized clinical trial of cognitive behavioral therapy (CBT) versus acceptance and commitment therapy (ACT) for mixed anxiety disorders. Journal of Consulting and Clinical Psychology, 80, 750-765. doi:10.1037/a0028310

Bass, C., van Nevel, J. ve Swart, J. (2014). A comparison between dialectical behavior therapy, mode deactivation therapy, cognitive behavioral therapy, and acceptance and commitment therapy in the treatment of adolescents. International Journal of Behavioral Consultation and Therapy, 9, 4-8. doi:10.1037/h0100991

Brausch, A. M., ve Girresch, S. K. (2012). A review of empirical treatment studies for adolescent nonsuicidal self-injury. Journal of Cognitive Psychotherapy, 26, 3-18. doi:10.1891/0889-8391.26.1.3

Brink, A. J. ve Wissing, M. P. (2012). A model for a positive youth development intervention. Journal of Child ve Adolescent Mental Health, 24, 113. https://doi.org/10.2989/17280583.2012.673491

Canadian Mental Health Association. (t.y.). What's the difference between CBT and DBT? Xx.xx.xxxx tarihinde: https://www.heretohelp.bc.ca/qand-a/whats-the-difference-between-cbt-and-dbt adresinden erişilmiştir.

Edwards, O. W., Mumford, V. E. ve Serra-Roldan, R. (2007). A positive youth development model for students considered at-risk. School Psychology International, 28, 29-45. https://doi.org/10.1177/0143034307075673

Goldstein, T., Axelson, D. A., Birmaher, B. ve Brent, D. (2007). Dialectical behavior therapy for adolescents with bipolar disorder: A 1-year open trial. J Am Acad Child Adolesc Psychiatry, 46, 820-830. doi:10.1097/chi.0b013e31805c1613

Groves, S., Backer, H. S., van den Bosch, W. ve Miller, A. (2012). Dialectical behaviour therapy with adolescents. Child and Adolescent Mental Health, 17, 65-75. doi:10.1111/j.1475-3588.2011.00611.x 
Gülgez, Ö. ve Gündüz, B. (2015). Diyalektik davranış terapisi temelli duygu düzenleme programının üniversite öğrencilerinin duygu düzenleme güçlüklerini azaltmadaki etkisi. Çukurova Üniversitesi Ĕ̆itim Fakültesi Dergisi, 44, 191-208. doi:10.14812/cufej.2015.010

Harvey, P. ve Rathbone, B.H. (2013). Dialectical behavior therapy for at-risk adolescents. Oakland, CA: New Harbinger Publications, Inc.

Hjalmarsson, E., Kåver, A., Perseius, K., Cederberg, K. ve Ghaderi, A. (2008). Dialectical behaviour therapy for borderline personality disorder among adolescents and young adults: Pilot study, extending the research findings in new settings and cultures. Clinical Psychologist, 12, 18-29. doi:10.1080/13284200802069035

Hunnicutt-Hollenbaugh, M. (2018). Introduction and overview. In (M. Hunnicutt Hollenbaugh ve M.S. LewisEd.), Dialectical behavior therapy with adolescents: Settings, treatments, and diagnoses (p.1-18) içinde. New York, NY: Routlage

Hunnicutt Hollenbaugh, K. M. ve Lenz, A. S. (2018). Preliminary evidence for the effectiveness of dialectical behavior therapy for adolescents. Journal of Counseling \& Development, 96, 119-131. https://doi.org/10.1002/jcad.12186

Hunnicutt Hollenbaugh, M. ve Lewis, M.S. (2018). Dialectical behavior therapy with adolescents: Settings, treatments, and diagnoses. New York, NY: Routlage

Johnston, J. A. Y., O'Gara, J. S. X., Koman, S. L., Baker, C. W., ve Anderson, D. A. (2015). A pilot study of Maudsley family therapy with group dialectical behavior therapy skills training in an intensive outpatient program for adolescent eating disorders: Family therapy and dialectical behavior therapy. Journal of Clinical Psychology, 71, 527-543. doi:10.1002/jclp.22176

Lenz, A. S. ve Del Conte, G. (2018). Efficacy of dialectical behavior therapy for adolescents in a partial hospitalization program. Journal of Counseling E Development, 96, 15-26. https://doi.org/10.1002/jcad.12174

Linehan, M. M. (1993). Cognitive-behavioral treatment of borderline personality disorder. New York, NY: Guilford Press.

Linehan, M. M. (2015a). DBT skills training manual. New York, NY: Guilford Press.

Linehan, M. M. (2015b). DBT skills training: Handouts and worksheets. New York, NY: Guilford Press. 
Miller, A. L., Rathus, J. H. ve Linehan, M. M. (2007). Dialectical behavior therapy with suicidal adolescents. New York, NY: Guilford Press.

Rathus, H. J. ve Miller, A. L. (2015). Dialectical behavior therapy skills manual for adolescents. New York, NY: The Guilford Press

Ricard, R.J., Fernandez, M.A., Ratanavivan, W., Armstrong, S.N., Karaman, M.A. ve Lerma, E. (2018). Working within school sites. (M. HunnicuttHollenbaugh ve M.S. Lewis Ed.), Dialectical behavior therapy with adolescents: Settings, treatments, and diagnoses (97-108) içinde. New York, NY: Routlage

Ricard, R. J., Lerma, E. ve Heard, C. C. C. (2013). Piloting a dialectical behavioral therapy (DBT) infused skills group in a disciplinary alternative education program (DAEP). The Journal for Specialists in Group Work, 38, 285-306. doi:10.1080/01933922.2013.834402

Sargın, M. ve Sargın, A.E. (2015). "Yaşamaya değer bir hayat" için: Diyalektik davranışçı terapinin gelişimi ve temel ilkeleri. Türkiye Klinikleri J Psychiatry-Special Topics, 8(2), 64-70.

Üstündağ Budak, A. M. ve Özeke Kocabaş, E. (2019). Dialectical behavior therapy and skill training: Areas of use and importance in preventive mental health. Current Approaches in Psychiatry, 11, 192-204. doi:10.18863/pgy.411209

\section{Kaynakça Bilgisi / Citation Information}

Karaman, M. A. (2019). Ergenlerle diyalektik davranış terapisi. OPUSUluslararası Toplum Araştırmaları Dergisi, 14(20), 2098-2120. DOI: 10.26466/opus.604025 